\title{
Correction: International Olympic Committee consensus statement on pain management in elite athletes
}

Hainline B, Derman W, Vernec A, et al. International Olympic Committee consensus statement on pain management in elite athletes. Br J Sports Med 2017;51:1245-58. 10.1136/ bjsports-2017-097884.

Mark Stuart's affiliation is incorrect. It should be: BPharm FFRPS FRPharmS, BMJ, London, UK.

(C) Article author(s) (or their employer(s) unless otherwise stated in the text of the article) 2018. All rights reserved. No commercial use is permitted unless otherwise expressly granted.

Br J Sports Med 2018;52:206. doi:10.1136/bjsports-2017-097884corr1 